\title{
Appropriate Roles for the Subscriber, Publisher, Editor, Author, and Reviewer in the Archives of Plastic Surgery
}

\author{
Kun Hwang
}

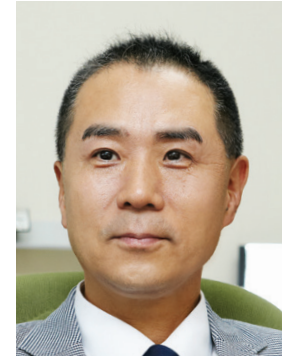

Ethics Editor, Archives of Plastic Surgery

Department of Plastic Surgery, Inha University School of Medicine, Incheon, Korea

\begin{abstract}
Authors, editors and reviewers, publishers, and subscribers all play their role in scientific journals. These 5 stakeholders are essential to journals. In this paper, firstly, I briefly summarize the role of each journal stakeholder and their respective goals. Secondly, the status of each participant in the Archives of Plastic Surgery is described. Finally, I propose an appropriate role and plan for each of them. Specific roles and responsibilities include the following: subscribers should welcome and submit the critiques of published papers in letters to the editor. Publishers should trust editors and provide them with adequate financial support for ongoing quality improvement of the journal. The editor-in-chief should be given a sufficient period of time-several years-to build up journal quality and train the incoming editor. The editors, including section editors, are also responsible for increasing the author pool. One editor might be designated a 'devil's referee', that is, a kind of devil's advocate with the responsibility of examining the originality of the manuscript, taking a skeptical view of the manuscript, and looking for holes in the methods and results of reported experiments. Authors' responsibilities include submitting manuscripts with scientific integrity and being ready to take responsibility for their articles even long after publication. Finally, reviewers' responsibilities include identifying similar articles not cited. Reviewers are also welcome to write a discussion on the article they review.
\end{abstract}

Keywords Journal article / Publishing / Role / Editorial policies

\section{INTRODUCTION}

Science is strengthened not by research alone, but by publication of original research articles in international scientific journals that are read by a global scientific community. The publication process involves author-editor interaction, for which both get credit once the article gets published-the author directly, the editor indirectly [1]. Authors submit a manuscript to the editor, who decides to accept or reject it. The editor then sends the manuscript to the reviewers for their opinion. Aside from the author, editor, and reviewer, publishers and subscribers play their role in scientific journals as well. These 5 stakeholders are all essential to a journal's success.

It has been about 2 and a half years since the first issue of the
Archives of Plastic Surgery (APS) appeared, and so it is worth taking stock of these 5 stakeholder roles, how they are playing out in APS, and what responsibility each stakeholder might have to participate more effectively. Thus, in this paper, I first briefly summarize the role and aims of each journal stakeholder. Second, I consider the current status of each APS participant. Finally, for each type of stakeholder, I propose an appropriate role and suggested future direction.

\section{BODY}

\section{Subscribers (readers)}

Subscribers pay the journal to access new information. They may usually take what is written in a published paper at face 
value. However, the research experience and clinical expertise of the author do not guarantee validity and relevant recommendations. Uncritical acceptance of information by subscribers potentiates the dissemination of misinformation [2].

My fear is that APS readers do not read each issue carefully and critically because of the relatively small number of submissions of letters to the editor offering opinions, addenda, or critiques of published papers. Letters to the editor should be welcomed by all APS stakeholders for their insight into and relevant critiques of published papers. Both the authors and subscribers should take responsibility for their roles in producing clinical and scientific knowledge, and this partnership can improve patient care [2].

\section{Publishers}

A publisher is a kind of businessperson who sells knowledge to a limited number of subscribers, including libraries. The publisher is motivated to increase the number of subscribers and sometimes to improve the publication quality.

The publisher and editor both have considerable power to shape the content and form of the final publication. It is important that a system of checks and balances is maintained, such that the publisher cannot have undue influence on journal content because it is the editor-in-chief who brings clinical and technical knowledge to the table without a profit motivation. One way to accomplish this is to ensure that the editor-in-chief has a sufficient length of tenure, and that the incoming editor-inchief is already familiar with the practicalities of journal publication by serving in the associate editor role or another key role in the editorial board. Currently, APS is working toward this goal by maintaining the same editor-in-chief and associate editor for the third year.

Publishers have other responsibilities in the journal ecosystem. They should develop new products that will both help scientists in their work and enable publishing to remain a viable economic business model so that publication companies can continue to prosper in the future [3]. The publisher must also trust the editor and allocate appropriate levels of financial support to build journal quality on an ongoing basis.

\section{Editors}

The editors select manuscripts suitable for publication while rejecting unsuitable manuscripts. Most journals use peer review to raise the quality of published content. However, since the process of peer review can be prone to biases towards ideas that affirm the prior convictions of reviewers and against innovation and radical new ideas, a system of editorial review should also be established [4]. In both systems, the editor is responsible to and communicates with the readers, the publisher, as well as the authors and reviewers.

Editors are central stakeholders in a number of ways, having responsibilities to and simultaneously depending on all of the other journal participants. For the readers to easily locate papers of interest, the editor must attempt to get the journal listed in as many databases as possible. At the same time, the editor depends on authors to submit quality papers of interest to readers. The editor welcomes papers that have originality and that may be likely to be cited in other papers. A key goal of the editor is to have the articles in his or her journal cited by other authors, thereby increasing the journal's impact factor. The editor also wants papers from other journals to cite his or her own journal, which can also increase the impact factor.

The editor also has a responsibility to increase the author pool through personal and professional connections. Section editors share this responsibility. The editor may also find it helpful to designate a 'devil's referee,' a sort of devil's advocate who is responsible for examining the originality of a manuscript. The 'devil's referee' should take a skeptical view of the manuscript, looking for holes in the methods and results of the experiment, and insisting that the paper contain etwas neues (something new) [5].

The editor of a new journal may face a limited author pool since a journal is not well recognized internationally. The present editor-in-chief of APS has successfully listed APS in PubMed, PubMed Central, and Scopus, but not yet in Science Citation Index (SCI). He is in his third year, with one more year of his term remaining. It is not certain he can continue after 2014, given the time commitment and budget limitations. The other stakeholders must rally around the editor-in-chief to ensure that he has the proper resources.

\section{Authors}

The authors' primary goal is to have their paper read by many readers and cited by other authors. Authors should carefully read the aim and scope section of the journal before selecting a journal for manuscript submission. Authors want their manuscript to be accepted to a journal listed in high-profile databases and one with a high impact factor. The higher the impact factor is, the greater possibility of the article being cited.

Since APS is not listed in SCI, it seems likely that Korean authors at university hospitals do not choose APS as their first journal for submission. As an ethics editor over the past two years, I have encountered cases of "salami slicing," "imalas," and duplicate publication, as well as plagiarism. In addition, a few thoughtless authors have made strong protests to the editors when their manuscripts were rejected. 
Authors have an important responsibility of submitting manuscripts with scientific integrity. They must be aware that they continue to be responsible for their article's contents even long after publication. It is recommended that in cases in which a paper has been rejected by APS, especially when legitimate problems have been identified with the manuscript, the authors not argue with the editor, but revise their manuscript and find another journal to which to submit their paper.

\section{Reviewers}

The peer review system is an important component of modern scientific publishing, and it is a great help to editors in deciding whether or not a submitted manuscript is suitable for publication. The manuscript reviewer is a key player in the manuscript processing system and journal publication process. The reviewer's responsibilities include protecting the integrity of a specialty, the reputation of the journal, and the welfare of human and animal subjects, as well as treating the author's manuscript with respect, fairness, and impartiality [6].

In APS, the quality and rigor of the reviewers has not yet been standardized. Some are prone to accept most papers, while others tend to reject more papers. Some recommend too many revisions, while others make too few suggestions. Most of the reviewers do not take sufficient time to seek out similar articles which are not cited (SANC).

In APS, the standardization of reviewers is needed through training in reviewers' workshops. In my case, when I have a manuscript to review, I hold a journal review club (JRC) session to gather the opinions of colleagues in my department. SANC is usually uncovered during a JRC.

In APS, reviewers are welcome to write a discussion on the article which they reviewed. This is a short response making public the kind of feedback that reviewers typically provide the authors during the review process. A quality discussion is of benefit not only to the authors, but also to readers, who can discover different perspectives on the research presented, and particularly newer scholars, who are still learning to read critically.

\section{CONCLUSIONS}

The responsibilities mentioned here are only a few of those required of each stakeholder in the APS journal publication process. However, they are representative of the many other responsibilities that form the role of each participant in the journal publication ecosystem, all of which depend on and reinforce each other. All of the stakeholders should take pride in meeting their obligations to the scholarly community because these seemingly mundane tasks all contribute to spreading clinical knowledge that raises the quality of care for our patients.

\section{REFERENCES}

1. Kachewar SG, Sankaye SB. Reviewer index: a new proposal of rewarding the reviewer. Mens Sana Monogr 2013;11:27484.

2. Shaughnessy AF, Slawson DC. Getting the most from review articles: a guide for readers and writers. Am Fam Physician 1997;55:2155-60.

3. Heller $S$. The changing role of a publisher and the publisher of the future. Drug News Perspect 2007;20:413-5.

4. Steinhauser G, Adlassnig W, Risch JA, et al. Peer review versus editorial review and their role in innovative science. Theor Med Bioeth 2012;33:359-76.

5. Hwang K. The need for a reviewer to play Devil's advocate. Arch Plast Surg 2013;40:171-2.

6. Peh WC, Ng KH. Role of the manuscript reviewer. Singapore Med J 2009;50:931-3.

Correspondence: Kun Hwang

Department of Plastic Surgery, Inha University School of Medicine, 27 Inhang-ro, Jung-gu, Incheon 400-711, Korea

Tel: +82-32-890-3514, Fax: +82-32-890-2918, E-mail: jokerhy@inha.ac.kr

No potential conflict of interest relevant to this article was reported.

Received: 11 Jun 2013 • Revised: 23 Jun 2013 • Accepted: 24 Jun 2013 pISSN: 2234-6163 • elSSN: 2234-6171

http://dx.doi.org/10.5999/aps.2013.40.6.663 • Arch Plast Surg 2013;40:663-665 